\title{
IS- 256
}

Single and Polycrystal Resistivity Relationships

for Yttrium.

J. K. Alstad, R. V. Colvin*, and S. Legvold

Institute for Atomic Research and Department of Physics

Iowa State University, Ames, Iowa

\begin{abstract}
Different proposals for calculating polycrystal resistivities from single crystal values are applied to yttrium metal. It is shown that a simple average yielding $\rho_{\text {Pohy }}=\frac{1}{3}\left(2 \rho_{+}+P_{11}\right)$ gives the best fit to experimental data.
\end{abstract}

Contribution No. 994. Work was performed in the Ames Laboratory of the U. S. Atomic Energy Commission.

* Presently at the Edgar C. Bain Laboratory of the United States Steel Corporation, Monroeville, Pennsylvania. 


\section{DISCLAIMER}

This report was prepared as an account of work sponsored by an agency of the United States Government. Neither the United States Government nor any agency Thereof, nor any of their employees, makes any warranty, express or implied, or assumes any legal liability or responsibility for the accuracy, completeness, or usefulness of any information, apparatus, product, or process disclosed, or represents that its use would not infringe privately owned rights. Reference herein to any specific commercial product, process, or service by trade name, trademark, manufacturer, or otherwise does not necessarily constitute or imply its endorsement, recommendation, or favoring by the United States Government or any agency thereof. The views and opinions of authors expressed herein do not necessarily state or reflect those of the United States Government or any agency thereof. 


\section{DISCLAIMER}

Portions of this document may be illegible in electronic image products. Images are produced from the best available original document. 
$-2-$

INTRODUCTION

It is reasonable to expect that a general relation exists between the principal resistivities of a single crystal and the isotropic resistivity of a polycrystalline sample of the same substance. "There is, however, little agreement in the literature as to the form of this relation; several methods of calculating the polycrystal resistivity have been proposed. Voigt ${ }^{1}$ suggests

$$
\sigma_{p \circ / y}=\frac{1}{3}\left(2 \sigma_{1}+\sigma_{11}\right)
$$

which is the same as

$$
P_{p 01 y}=\frac{3 p_{1} p_{11}}{2 \rho_{11}+p_{1}},
$$

where $P_{11}$ and $P_{\perp}$ are the principal resistivities of a hexagonal. crystal measured parallel and perpendicular to the axis of symmetry, and where $\rho_{1}=\frac{1}{\sigma_{1}}, \rho_{11}=\frac{1}{\sigma_{11}}, \rho_{p \circ / y}=\frac{1}{\sigma_{p} / y}$.

Andrade and Chalmers ${ }^{2}$ obtain

$$
\rho_{p_{01}}=\frac{\sqrt{\rho_{1}\left(\rho_{11}-\rho_{2}\right)}}{\tan ^{-1} \sqrt{\left(p_{11}-\rho_{+}\right) / \rho_{2}}}
$$

for the case $\rho_{11}>\rho_{1}$. This is equivalent to (2)

$$
\rho_{p \rightarrow y}=\frac{\sqrt{\rho_{\perp}\left(\rho_{1}-\rho_{11}\right)}}{\tanh ^{-1} \sqrt{\left(\rho_{\perp}-\rho_{11}\right) / \rho_{\perp}}}
$$


for $\quad \rho_{\perp}>\rho_{11} \cdot$ Bruggeman ${ }^{3}$ proposes

$$
\sigma_{p \circ l_{y}}=\frac{1}{4}\left[\sigma_{1}+\sqrt{\sigma_{1}\left(8 \sigma_{11}+\sigma_{1}\right)}\right],
$$

or

$$
\hat{\beta}_{p_{\text {oly }}}=4 /\left[\frac{1}{\rho_{1}}+\sqrt{\frac{1}{\rho_{+}}\left(\frac{8}{\rho_{1 !}}+\frac{1}{\rho_{+}}\right)}\right] .
$$

Another method, ${ }^{4}$ which has been proposed more recently, yields

$$
\rho_{\text {poly }}=\frac{1}{3}\left(2 P_{+}+P_{11}\right) .
$$

This relation is the result of an average over the total solid angle of the well-known expression,

$$
\rho(\theta)=\rho_{i 1} \cos ^{2} \theta+\rho_{\perp} \sin ^{2} \theta,
$$

for the resistivity along an arbitrary direction of current flow in a hexágonal crystal. 5

Several attempts 2,3 to resolve this question experimentally have been indecisive; if the anisotropy ratio, $\rho_{1} / \rho_{11}$ is very near unity, the small difference between values given by any of equations 1-4 is masked by the probable error of the experiment. Recently Hall et al. 6 have reported the principal single-crystal resistivities of yttrium (see Table II). Their values at $300^{\circ} \mathrm{K}$ lead to the exceptionally high anisotropy ratio of

$$
\rho_{1} / \rho_{11}=2.07,
$$


which suggests that a fair test of the various calculated $\rho_{\text {poly }}$ might by made through a comparison with measurements on polycrystalline samples of this metal.

\section{EXPERIMENTAL PROCEDURE}

The polycrystalline yttrium data were obtained from three separate arc-melted samples produced in this Laboratory. The finished samples were cylinders 2 inches long and 3/16 inch in diameter. They were annealed at $900^{\circ} \mathrm{C}$ for two hours, cold swaged with a $10 \%$ reduction in diameter and reannealed at $800^{\circ} \mathrm{C}$ for one hour. These operations eliminated grain orientation and reduced the size of the grains. The samples were examined and found to have an average grain diameter of $0.14 \mathrm{~mm}$. Analysis by back-reflection $x$-ray methods showed that the grains were randomly oriented. Table I lists the impurities found by spectrographic. and vacuum fusion analyses on one of the samples, Y-II. Except for the silicon content which is unusually high, these values are representative of the other samples.

The resistivities of the three samples were measured using the method and apparatus described by Colvin et al. 7

\section{RESULI'S AND CONCLUSIONS}

The electrical resistivity of a representative sample (Y-II) in the temperature range $1.3^{\circ} \mathrm{K}$ to $300^{\circ} \mathrm{K}$ is shown in Fig. 1. Table II shows the residual resistivities together with the resistivities at $300^{\circ} \mathrm{K}$ (less residuals) 
of the three polycrystalline samples and the single crystals. The calculated results of substituting the measured principal single-crystal resistivities into Eqs. 1-4 are also included. The last column of this table is depicted graphically in Ftg. 2. Also shown are the cotimated probable errors, taken to be $\pm 1 \%$ for the experimental values and $\pm 2 \%$

for the calculated values. It is clear that the best fit to the experimental data is obtained from Eq. 4. It therefore seems appropriate to use this relation for hexagonal metals.

\section{ACKNOW LEDGEMENTS}

The authors are indebted to the following members of the Ames Laboratory staff: Mr. F. Schmidt and Mr. C. Haberman for furnishing the samples, and Mr. E. Gibson for annealing the samples and measuring the grain size. 


\section{Table I.}

Impurity Analysis of Sample Y-II. (Values in \%).

$E_{r} \leq 0.005 ; H_{0} \leq 0.05 ; \quad D y \leq 0.005 ; T b \leq 0.04 ; . G d \leq 0.01 ; S m \leq 0.05 ;$

$\mathrm{Ca}<0.02 ; \mathrm{Fe}, 0.05 ; \mathrm{Mg}<0.01 ; \mathrm{Si}, 0.5 ; \mathrm{Ta}<0.1 ; \mathrm{Cr}, 0.1,02,0.033 ;$

$\mathrm{Mn}, \mathrm{Ti}, \mathrm{Cu}, \mathrm{Ni} ; \mathrm{Ca}, \mathrm{Al}, \mathrm{Cr}, \mathrm{Mg}, \mathrm{Si}, \mathrm{Bi}$, trace present.

Table II.

Comparison of Experimental and Calculated Results.

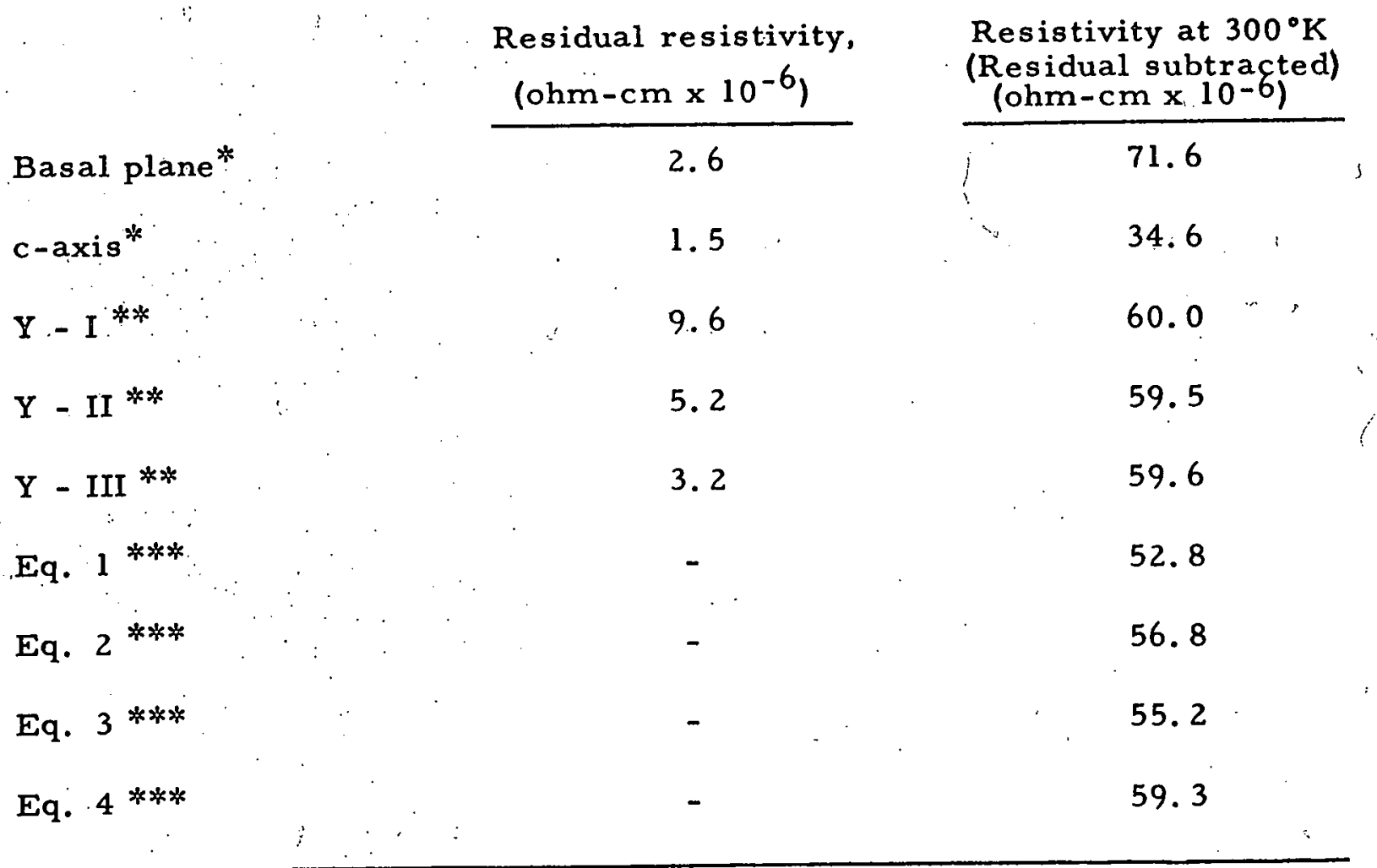

$$
\begin{aligned}
& \text { * Hall et al. } 6 \\
& \text { ** Present experimental results } \\
& \text { *3*\%* } \\
& \text { results into Eqs. } 1-4 .
\end{aligned}
$$




\section{FIGURE CAPTIONS}

Fig. 1. The electrical resistivity of yttrium (Y-II) as a function of temperature.

Fig. 2. Graphical presentation of results showing probable errors. 


\section{REFERENCES}

1. W. Voigt, Lehrbuch der Kristallphysik, (B. G. Teubner, Leiptig, 1928) 959.

2. E. N. da C. Andrade and B. Chalmers, Proc. Koy. Soc. (London) A $138,413(1932)$.

3. D. A. G. Bruggeman, Ann. der Physik 25, 645 (1936).

4. J. L. Nichols, J. Appl. Phys. 26, 470 (1955).

5. W. Boas and J. K. Mackenzie, Progress in Metal Physics, edited by B. Chalmers (New York, Interscience Publishers, Inc., 1950), Vol. II, p. 90.

6. P. M. Hall, S. Legvold and F. H. Spedding, Phys. Rev. 116, 1446 (1959).

7. R. V. Colvin, S. Legvold and F. H. Spedding, Phys. Rev. 120, $741(1960)$. 


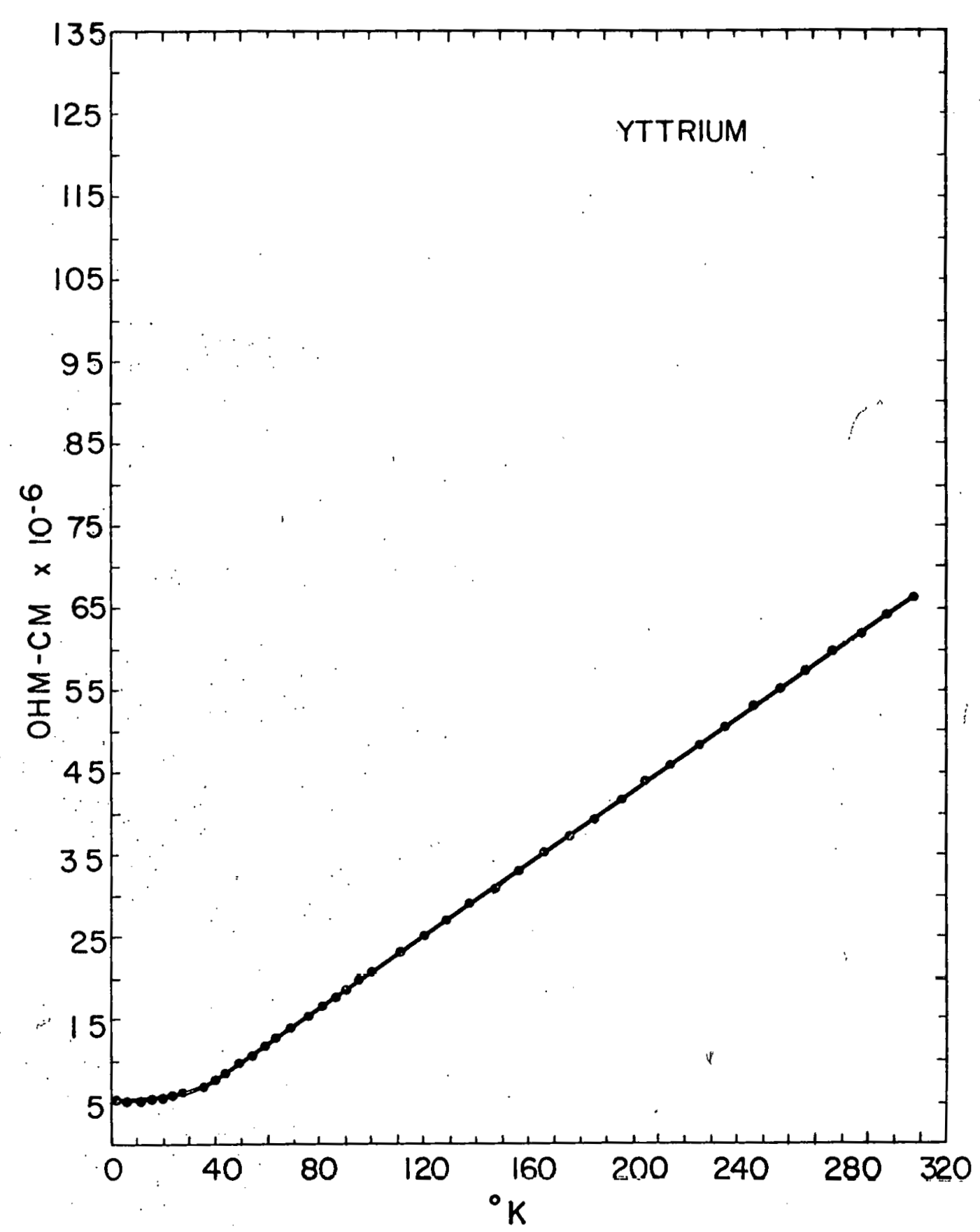

Fig. 1. The electrical resistivity of yttrium ( $Y-I I)$ as a function of temperature. 
$-10-$

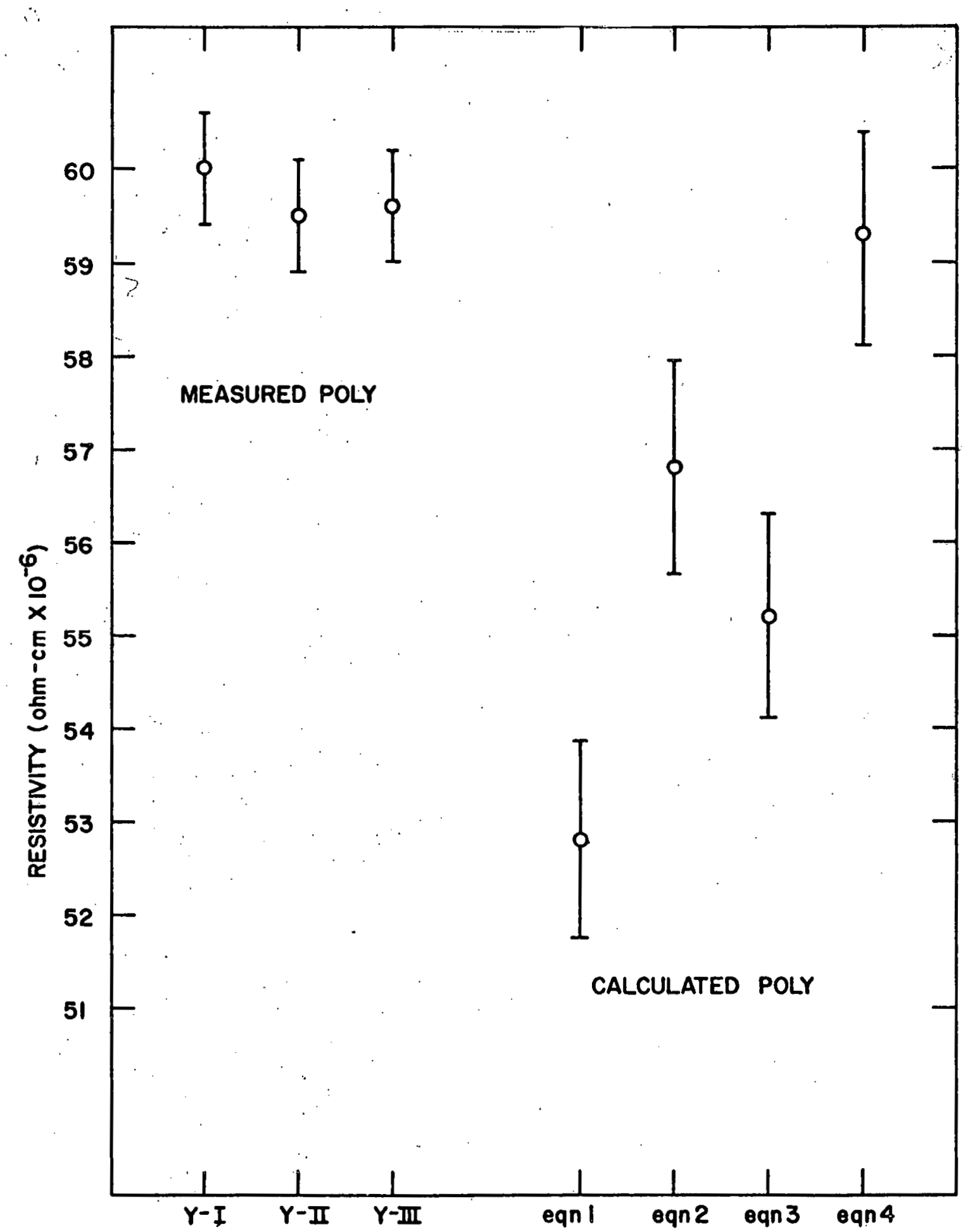

Fig, 2. Graphical presentation of results showing probable errors. 